\title{
Structural and Morphological Effects of Alkyl Side Chains on Flanking Thiophenes of Diketopyrrolopyrrole Polymers for Organic Photovoltaic Devices
}

\author{
Chi Kin Lo and John R. Reynolds
}

School of Chemistry and Biochemistry, School of Materials Science and Engineering, Center for Organic Photonics and Electronics, Georgia Tech Polymer Network, 901 Atlantic Drive, Georgia Institute of Technology, Atlanta, GA 30332, USA

\begin{abstract}
Two donor polymers containing thiophene (T) and thienothiophene (TT) as the electron rich, and diketopyrrolopyrrole (DPP) as the electron poor, moieties were synthesized and utilized in organic photovoltaic (OPV) devices. We appended $n$-decyl side chains onto the thiophenes directly adjacent to the di-hexyldecyl substituted DPP center core to ensure solubility of the resulting polymers. We observed the impact of active layer morphologies, as determined by grazing-incidence wide angle X-ray scattering (GIWAXS) and atomic force microscopy (AFM), on solar cell characteristics. Compared to devices fabricated with the thiophene-containing polymer P(T-DPP), devices with poly(thienothiophene-alt-diketopyrrolopyrrole), P(TT-DPP), exhibited higher average power conversion efficiency (PCE) of 3.0\% and short circuit current $\left(J_{s c}\right)$ of $10.4 \mathrm{~mA} / \mathrm{cm}^{2}$. This higher performance is attributed to an improved charge transport and extraction as a result of a greater degree of intermixing in P(TT-DPP) and fullerene thin film.
\end{abstract}

\section{Graphical abstract}

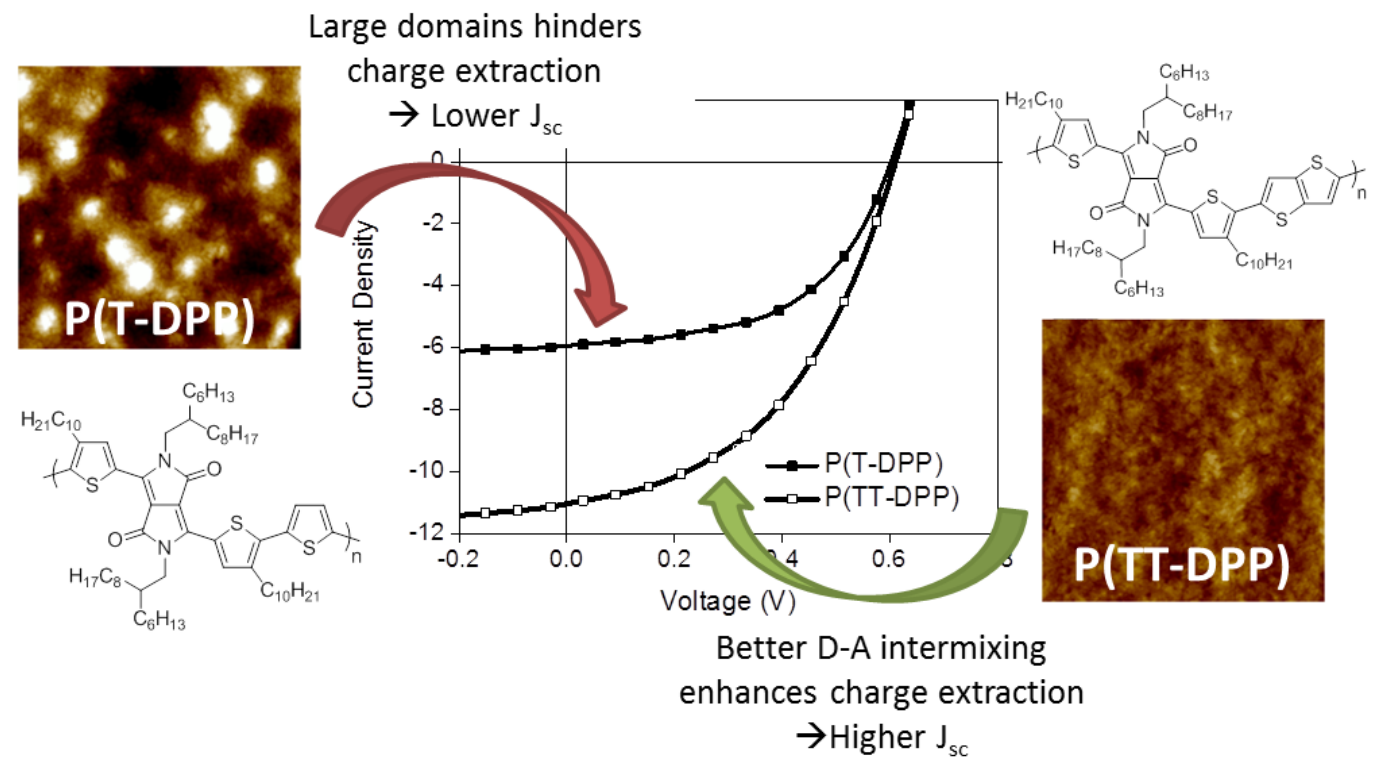




\section{Keywords}

Donor conjugated polymer

Low band gap

Organic photovoltaics

Diketopyrrolopyrrole

\section{Introduction}

The field of organic photovoltaics (OPVs) has developed into an active research topic in applied polymer, materials, and chemical sciences over the past decade due to the continuous improvement in device performance. The solution-processability of the organic active layer materials allows for the development of low-cost, flexible, and lightweight solar devices which have the potential to be manufactured through a variety of high-throughput roll-to-roll printing methods. ${ }^{1,2,3}$ The active layers in these OPV devices are usually made up of a bulk heterojunction (BHJ) design with an interpenetrating network consisting of $\pi$-conjugated organic oligomeric or polymeric materials as donors and fullerenes as acceptors. This bicontinuous network aids in charge separation and transport within the device. ${ }^{4}$ The donor materials can be easily synthesized by cross coupling reactions such as Stille, Suzuki, and direct arylation polymerizations. ${ }^{5}$ These polymers contain both electron-rich and electron-poor moieties in order to achieve low bandgap materials suitable for light absorption and charge generation. ${ }^{6,7,8,9}$ Some of the most widely used electron-poor building blocks in materials for OPVs include isoindigo (iI), benzothidiazole (BTD), thienopyrrolodione (TPD), and diketopyrrolopyrrole (DPP). ${ }^{10}$

In the 1970s, Donald Farnum and coworkers attempted to synthesize an unsaturated $\beta$-lactam via the Reformatsky reaction. ${ }^{11}$ Instead of the targeted $\beta$-lactam, they obtained a bright red solid, a dilactam now known as DPP. Because of DPP's structural similarity to other industrial organic pigments, Ciba investigated new synthetic strategies to improve the yield, reaction scale, and

product functionality. ${ }^{12}$ Today, the most popular synthetic route to prepare DPP involves a 
condensation reaction between aryl nitriles and succinic acid esters. Because of the aryl nitrile precursor, the DPP core is directly flanked with two aromatic rings, such as thiophenes, thienothiophenes, benzenes, furans, and selenophenes, which are usually unsubstituted. ${ }^{13,14}$ Because these flanking aromatic groups can be functionalized, new DPP-based low bandgap conjugated materials can be easily synthesized contributing to the popularity of DPP usage in organic electronics. ${ }^{15}$ Further, the DPP core can be $N$-alkyl functionalized, thus by attaching side chains with different length and branching point, both on the DPP cores ${ }^{16}$ and along the polymer backbones, ${ }^{17,18}$ fine adjustment on solution processability and structural property can be achieved. The utilization of DPP as a building block in oligomeric and polymeric photoactive materials ${ }^{15,19,20,21}$ has led to highly performing OPV devices with power conversion efficiencies (PCEs) approaching $10 \%{ }^{22,23}$

In this study, we have successfully synthesized DPP units with $n$-decyl side chains attached to the 4-position of the adjacent thiophenes. The resulting polymers have enhanced solubilities in common organic solvents (up to $40 \mathrm{mg} / \mathrm{mL}$ ). The two polymers show similar physical, structural, and optoelectronic, allowing us to carry out a morphological and structural study and their impacts on OPV device performance as a result of the added side chains. Figure 1a and $1 \mathrm{~b}$ schematically illustrate how incorporated side-chains might affect intermolecular packing distances, both $\pi-\pi$ and interlamellar relative to non-alkylated polymers. Our polymers with the added side chains are shown to exhibit different degrees of intermixing and domain size which impacts OPV device performance as a result of greater $\pi-\pi^{24}$ and lamellar intermolecular spacings in both pristine polymer and polymer:fullerene blend films. Our work shows that the attachment of alkyl side chains along polymer backbones can be used as an effective strategy to control nanoscale intermolecular interaction between neighboring polymer units. 

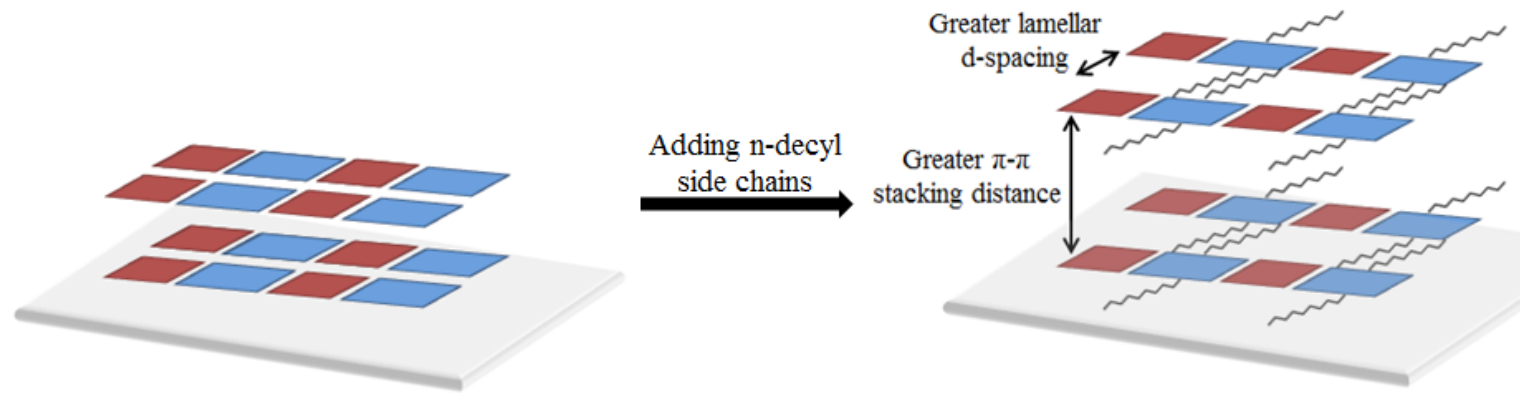

Fig. 1. Schematic illustration of the proposed polymer packing models comparing a) the nonalkylated polymers and b) the polymers with the addition of $n$-decyl side chains on the flanking thiophenes. The additional side chains lead to greater $\pi-\pi$ and lamellar intermolecular spacings.

\section{Experimental Details}

All precursors and monomers were synthesized according to literature methods ${ }^{25,26,27}$ as shown in Scheme S1. Polymer characterization data, including gel permeation chromatography (GPC), Thermogravimetric analysis (TGA), and differential scanning calorimetry (DSC) are included in the Supporting Information.

\subsection{Synthesis of Polymers}

\subsubsection{Synthesis of Poly(thiophene-alt-diketopyrrolopyrrole), $\mathbf{P ( T - D P P )}$}

To a $25 \mathrm{ml}$ Schlenk tube with 2,5-bis(trimethylstannyl) thiophene (33.4 $\mathrm{mg}, 0.082 \mathrm{mmol})$, $\mathrm{Pd}_{2}(\mathrm{dba})_{3}(3.0 \mathrm{mg}, 4 \mathrm{~mol} \%$ ), and $\mathrm{P}(\mathrm{o}-\mathrm{tol}) 3$ (1.5 mg, $6 \mathrm{~mol} \%$ ), 3,6-bis(5-bromo-4-decyl-thiophen2-yl)-N,N'-bis(2-hexyldecyl)-pyrrolo[3,4-c]pyrrole-1,4-dione (M1) (96.8 mg, $0.082 \mathrm{mmol})$ was added under argon. The flask was subjected to three pump/purge cycles with argon. Toluene (3 ml) was added and the reaction mixture was heated to $95{ }^{\circ} \mathrm{C}$ and stirred for 72 hours. The reaction mixture was cooled to $60{ }^{\circ} \mathrm{C}$ and stirred for 12 hours with a spatula-tip amount of 
diethyldithiocarbamic acid diethylammonium salt (CAS\# 2391-78-8) to scavenge the palladium catalyst. The mixture was precipitated into methanol and filtered onto a PTFE membrane. The crude polymer underwent soxhlet extractions with methanol, acetone, hexane, and dichloromethane. The dichloromethane portion was concentrated under reduced pressure and precipitated into methanol and filtered onto a PTFE membrane. After drying under vacuum, the product was obtained as a blue-green solid ( $72 \mathrm{mg}, 80 \%)$.

${ }^{1} \mathrm{H}$ NMR (300 MHz, $\mathrm{CDCl}_{3}, \mathrm{ppm}$ ): $\delta 8.84$ (s), 7.05 (s), 4.03 (br), 2.91 (br), 1.99 (br), 1.77 (br), $1.23(\mathrm{~m}), 0.83(\mathrm{~m})$. GPC (1,3,4-trichlorobenzene at $140{ }^{\circ} \mathrm{C}$ vs polystyrene standards, RI): $\mathrm{M}_{\mathrm{n}}=11.4 \mathrm{~kg} / \mathrm{mol}, \bigoplus_{\mathrm{M}}=3.2$. Anal. Calcd for $\mathrm{C}_{70} \mathrm{H}_{112} \mathrm{~N}_{2} \mathrm{O}_{2} \mathrm{~S}_{3}(\%)$ : C, 75.62; H, 10.33; N, 2.52; S, 8.65. Found (\%): C, 74.63; H, 10.11; N, 2.40; S, 8.66.

\subsubsection{Synthesis of Poly(thienothiophene-alt-diketopyrrolopyrrole), P(TT-DPP)}

The synthesis of P(TT-DPP) followed the same procedure as the synthesis of P(T-DPP) with the following starting materials: $\quad$ M1 $\quad(96.0 \quad \mathrm{mg}, \quad 0.081 \quad \mathrm{mmol}), \quad 2,5-$ bis(trimethylstannyl)thieno[3,2-b]thiophene(37.6 mg, $0.081 \mathrm{mmol}), \mathrm{Pd}_{2}(\mathrm{dba}) 3(3.0 \mathrm{mg}, 4 \mathrm{~mol} \%)$, and $\mathrm{P}(\mathrm{o}-\mathrm{tol})_{3}(1.5 \mathrm{mg}, 6 \mathrm{~mol} \%)$. The product was obtained as a blue-green solid $(62 \mathrm{mg}, 66 \%)$.

${ }^{1} \mathrm{H}$ NMR (300 MHz, $\mathrm{CDCl}_{3}, \mathrm{ppm}$ ): $\delta 8.85$ (s), 7.11 (s), 4.04 (br), 2.91 (br), 1.96 (br), 1.77 (br), $1.26(\mathrm{~m}), 0.88(\mathrm{~m})$. GPC (1,3,4-trichlorobenzene at $140{ }^{\circ} \mathrm{C}$ vs polystyrene standards, RI): $\mathrm{M}_{\mathrm{n}}=12.0 \mathrm{~kg} / \mathrm{mol}, \bigoplus_{\mathrm{M}}=3.4$. Anal. Calcd for $\mathrm{C}_{72} \mathrm{H}_{112} \mathrm{~N}_{2} \mathrm{O}_{2} \mathrm{~S}_{4}$ (\%): C, 74.04; H, 9.84; N, 2.40; $\mathrm{S}$, 10.98. Found (\%): C, 73.05; H, 9.63; N, 2.41; S, 11.40. 


\subsection{Measurements and characterizations}

${ }^{1} \mathrm{H}$ and ${ }^{13} \mathrm{C}$ NMR spectra were collected using a Varian Mercury Vx $300 \mathrm{MHz}$ spectrometer. The chemical shifts were recorded in units of ppm with $\mathrm{CDCl}_{3}$ as the internal standard and referenced to the residual solvent peak, ${ }^{1} \mathrm{H}: \mathrm{d}=7.26 \mathrm{ppm},{ }^{13} \mathrm{C}: \mathrm{d}=77.23 \mathrm{ppm}$. The ${ }^{1} \mathrm{H}$ NMR spectra of the polymers can be found in Fig. S1. Elemental analyses were conducted by Atlantic Microlab, Inc. Absorption spectra were measured using a Varian Cary 5000 Scan UV-Vis-NIR spectrophotometer. The molecular weights of the polymers were determined by gel permeation chromatography (GPC) relative to a polystyrene standard. The chromatograms can be found in Fig. S2. Thermogravimetric analyses as shown in Fig. S3 were carried out on a PerkinElmer Pyrus 1 TGA under a continuous flow of nitrogen with a heating rate of $10{ }^{\circ} \mathrm{C} / \mathrm{min}$. Fig. S4 shows the differential scanning calorimetry results, which were performed using a TA Instruments Q200 DSC with a heating rate and a cooling rate of $10{ }^{\circ} \mathrm{C} / \mathrm{min}$. Electrochemistry was performed using an EG\&G Princeton Applied Research model 273A potentiostat-galvanostat. Cyclic voltammograms (scan rate $50 \mathrm{mV} / \mathrm{s}$ ) and differential pulse voltammograms (step size $2 \mathrm{mV}$, step time $50 \mathrm{~ms}$, pulse amplitude $100 \mathrm{mV}$ ) of the polymers were collected using $0.01 \mathrm{~cm}^{2} \mathrm{Pt}$ disc electrodes in $0.5 \mathrm{M} \mathrm{TBAPF} /$ acetonitrile, with a $\mathrm{Ag} / \mathrm{Ag}^{+}$reference electrode $(0.01 \mathrm{M} \mathrm{AgNO}$ ) and a Pt flag counter electrode. The atomic force microscopy (AFM) images $(2 \mu \mathrm{m} \times 2 \mu \mathrm{m})$ were obtained with a Bruker Icon AFM microscope operating in tapping mode.

\subsection{Grazing-Incidence Wide Angle X-Ray Scattering (GIWAXS) experiments}

GIWAXS measurements were performed on beamline 11-3 at the Stanford Synchrotron Radiation Lightsource. Polymer and polymer: $\mathrm{PC}_{71} \mathrm{BM}$ blend thin films were spin-coated onto silicon wafers with the same conditions as in device fabrications. The photon energy was 12.7 
$\mathrm{keV}$. The incidence angle was set to $0.12^{\circ}$ for maximum level of diffraction. The scattering pattern was detected by a MAR345 imaging plate located at a distance of $300 \mathrm{~mm}$ from the sample center. The images were calibrated using a lanthanum hexaboride ( $\left.\mathrm{LaB}_{6}\right)$ standard. Each substrate was loaded into a helium-purged chamber to reduce air scattering and beam damage to the samples. X-ray irradiation durations varied from one to five minutes depending on the desirable signal intensity. Images were analyzed using the WxDiff software. The signals were analyzed according to the modified Bragg's law, $q=2 \pi / \lambda$.

\subsection{Fabrication of Photovoltaic Devices}

Devices were fabricated in the conventional architecture (A1/Ca/Polymer:PC 71 BM/PEDOT:PSS/ITO). Patterned indium tin oxide (ITO) substrates were cleaned by sonication for 15 minutes each in $0.1 \%$ sodium dodecyl sulfate solution, ultrapure water (Millipore system, resistivity 18.2 M $\Omega . \mathrm{cm}$ ), acetone and isopropyl alcohol. The substrates were exposed to UV-ozone for two 10-minute treatments. Poly(3,4-ethylenedioxythiophene) polystyrene sulfonate (PEDOT:PSS) (45 nm) was spin-coated in air onto the ITO at 5,000 RPM for one minute. Polymer:PCBM blends (1:1.5 ratio, $20 \mathrm{mg} / \mathrm{ml})$, with and without $2.5 \%(\mathrm{v} / \mathrm{v}) 1,8-$ diiodooctane (DIO) as the processing additive, were dissolved in o-dichlorobenzene and stirred for 16 hours at $100{ }^{\circ} \mathrm{C}$ under argon. The active layer was deposited onto the substrate by spin coating at 800 RPM in an argon-filled glovebox. $10 \mathrm{~nm}$ of calcium, and subsequently $90 \mathrm{~nm}$ of aluminum, were evaporated onto the active layer at $10^{-6}$ torr through a metal mask to produce $0.07 \mathrm{~cm}^{2}$ active pixels. Current density-voltage (J-V) characteristics were recorded under argon with 2410 Keithley SourceMeter ${ }^{\circledR}$ SMU Instruments, with AM 1.5 G illumination at 100 $\mathrm{mW} / \mathrm{cm}^{2}$ intensity generated using a Newport Oriel 69907 power supply connected to a $150 \mathrm{~W}$ 
xenon arc lamp (Newport 6255) with collimating lenses in a Newport Oriel 94021A simulator lamp housing. Incident photon-to-current efficiency (IPCE) measurements were conducted in air using a setup consisting of a Newport 66485 xenon lamp, an Oriel ${ }^{\circledR}$ CS260 $20^{\text {TM }}$ VIS-NIR 1/4 m monochromator, and a Merlin ${ }^{\mathrm{TM}} 70104$ Digital Lock-in Radiometry Detector System.

\section{RESULTS AND DISCUSSION}

\subsection{Synthesis and Characterization of Polymers}

Scheme 1 outlines the Stille polymerizations process used to produce $\mathbf{P ( T - D P P )}$ and $\mathbf{P ( T T -}$ DPP) at $95{ }^{\circ} \mathrm{C}$ for 72 hours using $\mathrm{Pd}_{2}(\mathrm{dba})_{3}$ and $\mathrm{P}(\mathrm{o}-\text { tol })_{3}$ as the catalyst and ligand, respectively (Scheme 1). The palladium catalyst was handled only inside an argon-filled glovebox and stored at $-20{ }^{\circ} \mathrm{C}$ under an inert atmosphere. This is crucial in order to prevent catalyst decomposition which causes incorrect catalyst loading thus affecting molecular weight ${ }^{28}$ and the formation of $\operatorname{Pd}(0)$ nanoparticles which leads to homo-coupled fragments along the backbones. ${ }^{29}$ Diethyldithiocarbamic acid diethylammonium salt, a palladium scavenger, was used to remove palladium from the crude polymers. The concentrated crude polymer solutions were precipitated into methanol, filtered, and subsequently fractionated via soxhlet extraction. The dichloromethane fractions were concentrated and precipitated into methanol. The polymer precipitates were collected on PTFE membrane filters and dried under vacuum overnight to remove residual solvents. 

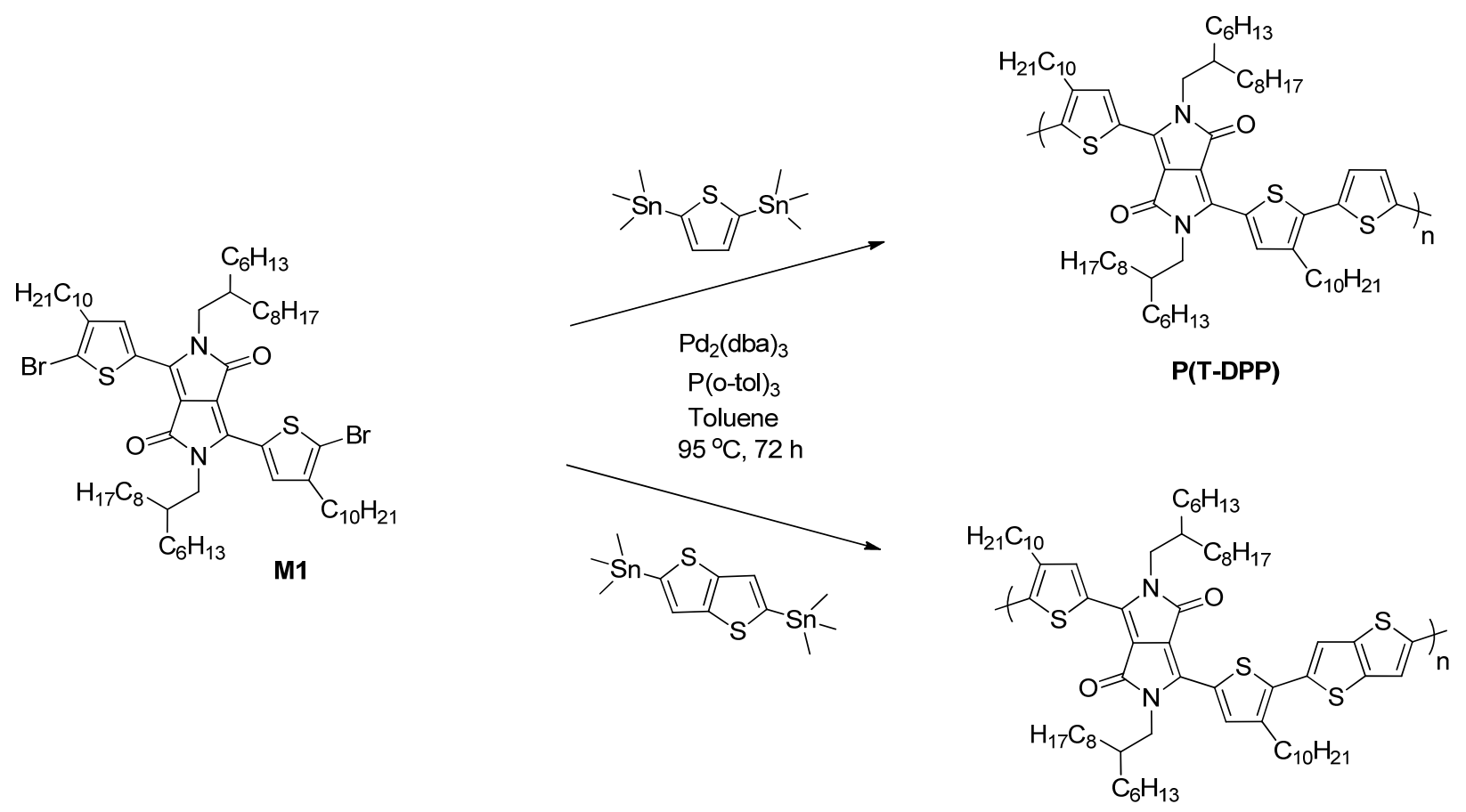

P(TT-DPP)

Scheme 1. Stille cross-coupling polymerizations of P(T-DPP) and P(TT-DPP)

\subsubsection{Physical and thermal stability}

Molecular weights and dispersities were measured using a high temperature 1,3,4trichlorobenzene GPC calibrated versus polystyrene standards. P(T-DPP) and P(TT-DPP) have number average molecular weights $\left(\mathrm{M}_{\mathrm{n}}\right)$ of 11.4 and $12.0 \mathrm{kDa}$ and molar mass dispersities $\left(\oslash_{\mathrm{M}}\right)$ of 3.2 and 3.4, respectively. Both P(T-DPP) and P(TT-DPP) show high thermal stabilities with decomposition temperatures (at 5\% weight loss)indicated by the TGA traces in Fig. S3. The DSC curves of the two polymers reveal the differences in their thermal behaviors. Fig. S4 shows that only P(T-DPP) displays crystallization and melting peaks, while P(TT-DPP) lacks any significant thermal transitions. Table 1 summarizes the physical properties of the polymers. 


\section{Table 1}

Molecular weights and thermal properties of P(T-DPP) and P(TT-DPP).

\begin{tabular}{|c|c|c|c|c|c|}
\hline Polymer & $\mathbf{M}_{\mathbf{n}}(\mathbf{k D a})^{\mathbf{a}}$ & $\mathbf{D}_{\mathbf{M}}^{\mathbf{a}}$ & $\mathbf{T}_{\mathbf{d}}\left({ }^{\circ} \mathbf{C}\right)^{\mathbf{b}}$ & $\mathbf{T}_{\mathbf{c}}\left({ }^{\circ} \mathbf{C}\right)^{\mathrm{c}}$ & $\mathbf{T}_{\mathbf{m}}\left({ }^{\circ} \mathbf{C}\right)^{\mathrm{c}}$ \\
\hline P(T-DPP) & 11.4 & 3.2 & 395 & 190 & 207 \\
\hline P(TT-DPP) & 12.0 & 3.4 & 387 & - & - \\
\hline \multicolumn{6}{|c|}{ calibration standard and 1,3,4-trichlorobenzene as the eluent. ${ }^{b}$ Decomposition temperature $\left(T_{d}\right)$ was determined by } \\
\hline \multicolumn{6}{|c|}{ thermogravimetric analysis at $5 \%$ weight loss with a heating rate of $10^{\circ} \mathrm{C} / \mathrm{min}$ under nitrogen. Crystallization $\left(\mathrm{T}_{\mathrm{c}}\right)$} \\
\hline and melting $\left(\mathrm{T}_{\mathrm{r}}\right.$ & ures were $\mathrm{m}$ & $\mathrm{red} \mathrm{h}$ & 1 scannin & etry with 1 & ad coolin \\
\hline
\end{tabular}

\subsubsection{Optical and Electrochemical Properties}

The solid-state absorption spectra of the polymers in Fig. 2 show that the onsets of absorptions begin in the infrared region revealing low optical bandgaps of 1.34 and $1.37 \mathrm{eV}$ for P(T-DPP) and P(TT-DPP), respectively. Both thin-film absorption onsets were red-shifted compared to the solution onsets, shown in Fig. S5, as a result of aggregation and backbone planarization in the solid state. Owing to the planar structure of the core, polymers containing DPP have shown strong intermolecular packing and aggregation properties. ${ }^{8,30,31}$ The thin-film absorptions show that both polymers possess similar absorption spectra with high energy peaks at ca. $400 \mathrm{~nm}$, low energy peaks at ca. $750 \mathrm{~nm}$, and shoulders just above $800 \mathrm{~nm}$. While thienothiophene linked polymers are generally believed to have a stronger tendency to aggregate than thiophene linked polymers as a result of its more extended $\pi$-face, ${ }^{32}$ this effect is absent in our case. 


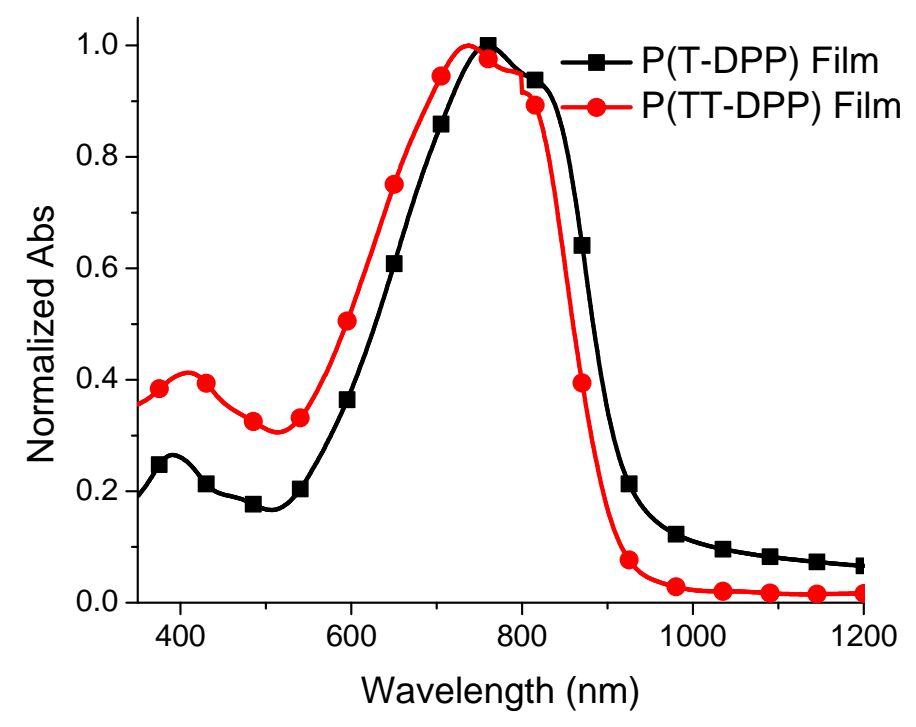

Fig. 2. Normalized thin film absorption spectra of P(T-DPP) and P(TT-DPP). The films were spin-coated onto glass substrates from $5 \mathrm{mg} / \mathrm{ml}$ chloroform solutions.

Electrochemical experiments were performed on the two polymers in an argon-filled glovebox. The ionization potentials (IPs) were estimated using the oxidation onsets of the differential pulse voltammetry (DPV) scans; the electron affinities (EAs) were estimated by the onsets of reductive DPV scans. Both polymers have electrochemical energy gaps (Egap) greater than their optical energy gaps, a phenomenon that has been observed in other conjugated polymers with similar backbones. ${ }^{33,34}$ Unlike in electrochemical experiment when free charge carriers are formed, only bound excitons form when the conjugated polymers are excited photophysically. ${ }^{35}$ As shown in Fig. 3, both polymers have similar electrochemically determined IP and EA levels, and Egap of ca. $1.90 \mathrm{eV}$. The EA levels of the polymers are ca. $0.5 \mathrm{eV}$ higher than that of $\mathrm{PC}_{71} \mathrm{BM},{ }^{36}$ which allows sufficient driving force for charge transfer from the donors to the fullerene acceptor. As summarized in Table 2, the similarities in the optical and 
electrochemical properties of the two polymers make them good candidates to explore morphological and structural effects on OPV device performance.
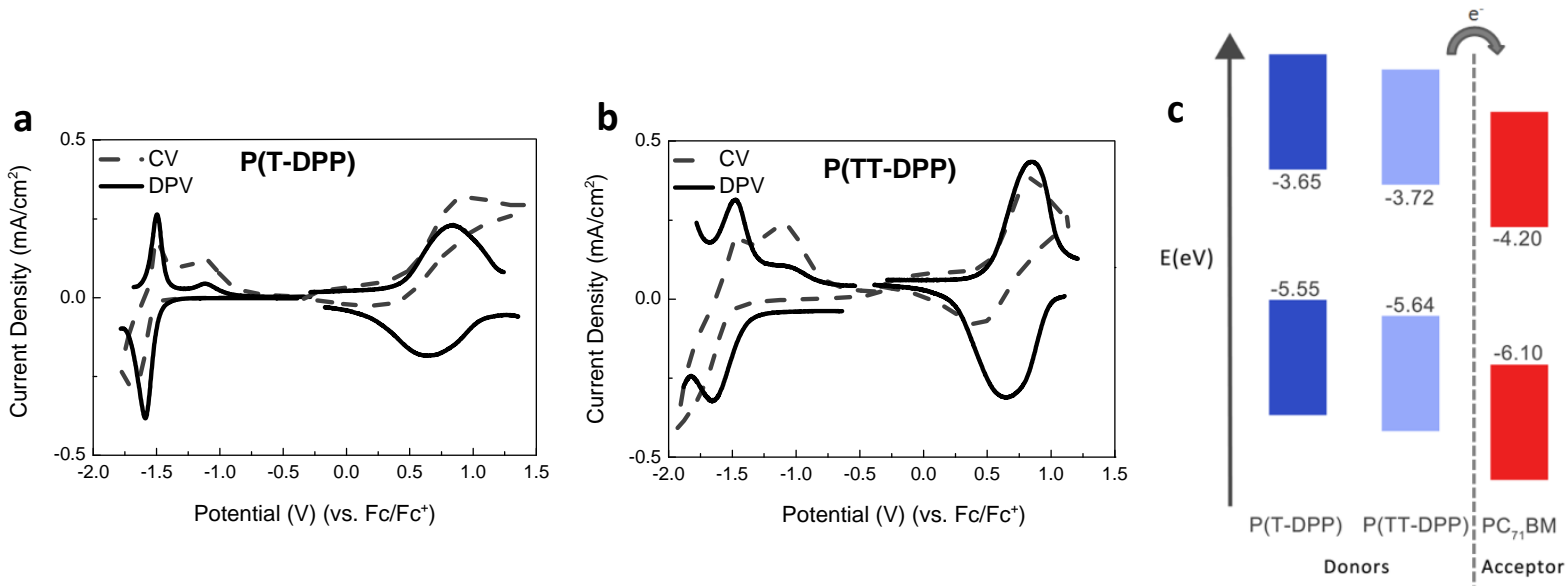

Fig. 3. Thin film cyclic voltammetry (scan rate $50 \mathrm{mV} / \mathrm{s}$ ) and differential pulse voltammetry (step size $2 \mathrm{mV}$, step time $50 \mathrm{~ms}$, pulse amplitude $100 \mathrm{mV}$ ) of (a) P(T-DPP) and (b) P(TTDPP). (c) Energy level diagram of the polymers compared to $\mathrm{PC}_{71} \mathrm{BM}^{36}$ indicates energy levels are well-aligned between donor polymers and the fullerene acceptor for efficient charge transfer.

\section{Table 2}

Summary of absorption and electrochemical properties of P(T-DPP) and P(TT-DPP).

UV-Vis-NIR

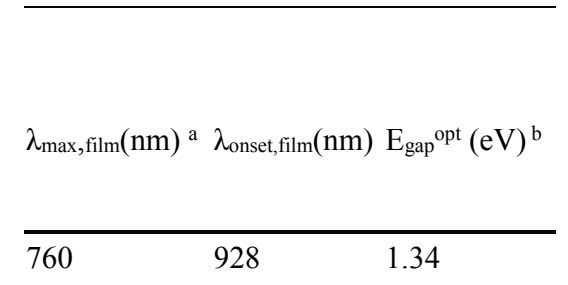

P(T-DPP)

P(TT-DPP) 739

907

1.37

0.65

$-1.65$
Electrochemistry

$\overline{\mathrm{CV}} \mathrm{DPV}$

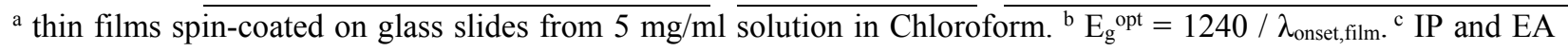
values were calculated by assuming $\mathrm{SCE}$ to be $4.74 \mathrm{eV}$ vs. vacuum and $\mathrm{Fc} / \mathrm{Fc}^{+}$to be $+0.38 \mathrm{eV}$ with respect to $\mathrm{SCE}$. 


\subsubsection{Comparing Solar Performance With Film Morphology}

BHJ OPV devices were fabricated with the polymers as donors and $\mathrm{PC}_{71} \mathrm{BM}$ as the acceptor in the active layers. Conventional architectures with PEDOT:PSS on top of patterned ITO substrates and reflective calcium/aluminum back electrodes were used. A summary of device performance is presented in Table 3. Devices with DIO as a processing additive $(2.5 \% \mathrm{v} / \mathrm{v})$ resulted in higher short circuit currents $\left(J_{s c}\right)$. It has been shown that the addition of DIO leads to a larger extent of interconnected regions within the active layers, improving charge transport and collection and thus higher $\mathrm{J}_{\mathrm{sc} .}{ }^{37}$ The addition of DIO often improves fill factors (FFs), but this is not the case for both of the polymers in this study. Since FF is related to the interfacial charge recombination in the BHJ active layer, lower FFs in the devices suggests that charge recombination is enhanced for both polymers with the addition of DIO. This may be a result of improved intermixing between the polymer and fullerene, ${ }^{38,39}$ which will be discussed in detail in the next section. Nevertheless, adding DIO into the active layers boosts the $\mathrm{J}_{\mathrm{sc}}$ and thus the device performance for both polymers, with P(TT-DPP) achieving an average PCE of $3.00 \%$ and $\mathbf{P}$ (T-DPP) at $1.86 \%$. The J-V characteristics in Fig. 4a show that the higher performance is a result of higher $J_{s c}\left(10.45\right.$ vs. $\left.5.50 \mathrm{~mA} / \mathrm{cm}^{2}\right)$ in the P(TT-DPP) devices. The $\mathrm{V}_{\text {oc }}$ of the devices from the two polymers are identical at ca. $0.6 \mathrm{~V}$. Voc is related to the effective bandgap, which is defined as the energy gap between the IP of the donor and the EA of the acceptor. ${ }^{40,41}$ The similarities between the redox properties of the two polymers as shown above validate the nearly identical $V_{o c}$ values observed. Fig. $4 \mathrm{~b}$ shows the IPCE curves measuring the incident photon to charge carrier efficiency of the same OPV devices. We observed a significant variation in the current generation efficiency between the two polymers, indicating that the devices had different charge extraction dynamics. The spectral responses, in both the polymer $\left(\lambda_{\max } \mathrm{ca} .600-900 \mathrm{~nm}\right)$ 
and PCBM regions $\left(\lambda_{\max }\right.$ ca. $480 \mathrm{~nm}$ ), indicate a higher efficiency for the photoinduced excitons in the $\mathbf{P ( T T - D P P ) :} \mathbf{P C}_{71} \mathbf{B M}$ device to dissociate into free carriers and contribute to photocurrent. ${ }^{42}$ It has been shown that the intermolecular structure and morphology within the OPV's active layer have strong impact on carrier mobilities and charge extraction efficiency, which in turn affect the generation of photocurrent and device performance ${ }^{43}$ The similarities in $\mathrm{V}_{\mathrm{oc}}$ and optoelectronic properties, in contrast to the differences in $\mathrm{J}_{\mathrm{sc}}, \mathrm{FF}$, and IPCE between these two polymers, indicate that the difference in the OPV device performance is related to the intermolecular interaction between the polymers and fullerene.
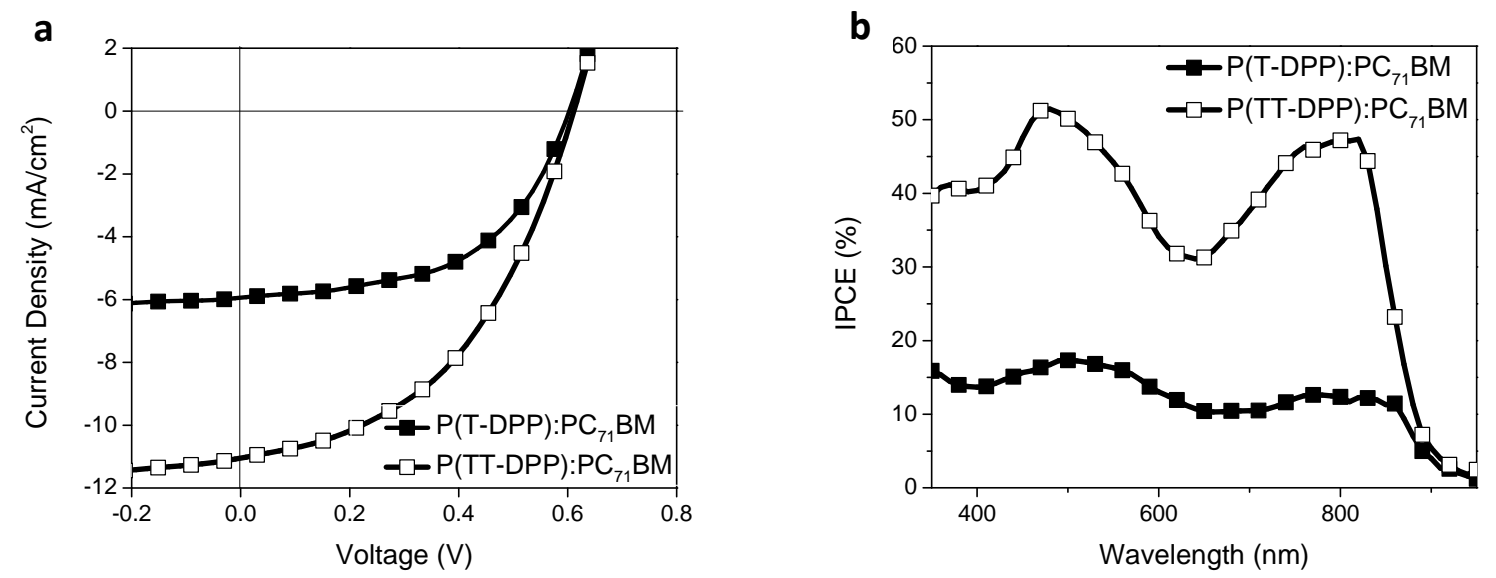

Fig. 4. (a) Current density-voltage characteristics and (b) incident photon-to-current efficiency of the polymers solar cells with $2.5 \% \mathrm{v} / \mathrm{v}$ DIO as additives. 


\section{Table 3}

P(T-DPP) and P(TT-DPP) OPV device performance with and without DIO as an additive.

\begin{tabular}{llllll}
\hline & DIO $(\mathrm{v} / \mathrm{v})$ & $J_{s c}\left(\mathrm{~mA} / \mathrm{cm}^{2}\right)$ & $V_{o c}(\mathrm{~V})$ & FF (\%) & PCE (\%) \\
\hline P(T-DPP) & None & $2.80 \pm 0.13(2.93)$ & $0.60 \pm 0.01(0.62)$ & $61.7 \pm 1.6(64.4)$ & $1.04 \pm 0.07(1.15)$ \\
& $2.5 \%$ & $5.50 \pm 0.24(5.88)$ & $0.62 \pm 0.01(0.64)$ & $54.4 \pm 2.3(55.5)$ & $1.84 \pm 0.04(1.91)$ \\
P(TT-DPP) & None & $4.77 \pm 0.17(5.04)$ & $0.62 \pm 0.01(0.64)$ & $54.1 \pm 0.7(55.1)$ & $1.60 \pm 0.06(1.70)$ \\
& $2.5 \%$ & $10.45 \pm 0.39(10.99)$ & $0.61 \pm 0.01(0.62)$ & $46.5 \pm 1.9(50.7)$ & $3.00 \pm 0.21(3.41)$
\end{tabular}

*OPV performance averaged over at least 8 devices.

To gain insight into the topography of the active layers, atomic force microscopy (AFM) was used to examine the morphology of the polymer:PC $71 \mathrm{BM}$ thin films. The AFM height images in

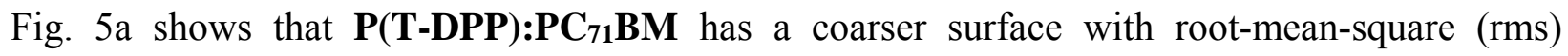
roughness of $3.39 \mathrm{~nm}$, compared to $\mathrm{rms}$ of $1.17 \mathrm{~nm}$ for P(TT-DPP):PC ${ }_{71} \mathbf{B M}$, shown in Fig. 5 b.

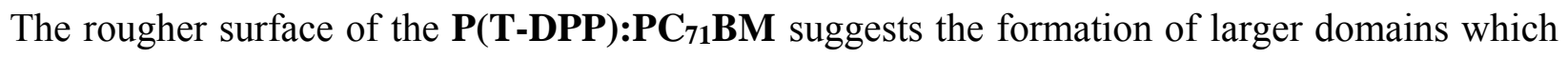
are visible in Fig. 5a. These larger domains in the P(T-DPP):PC $\mathbf{~}_{71} \mathbf{B M}$ device prevent excitons from diffusing to the donor/acceptor interface for efficient charge transfer and separation, explaining the lower IPEC, $J_{s c}$, and thus device performance in the devices. ${ }^{44}$ 

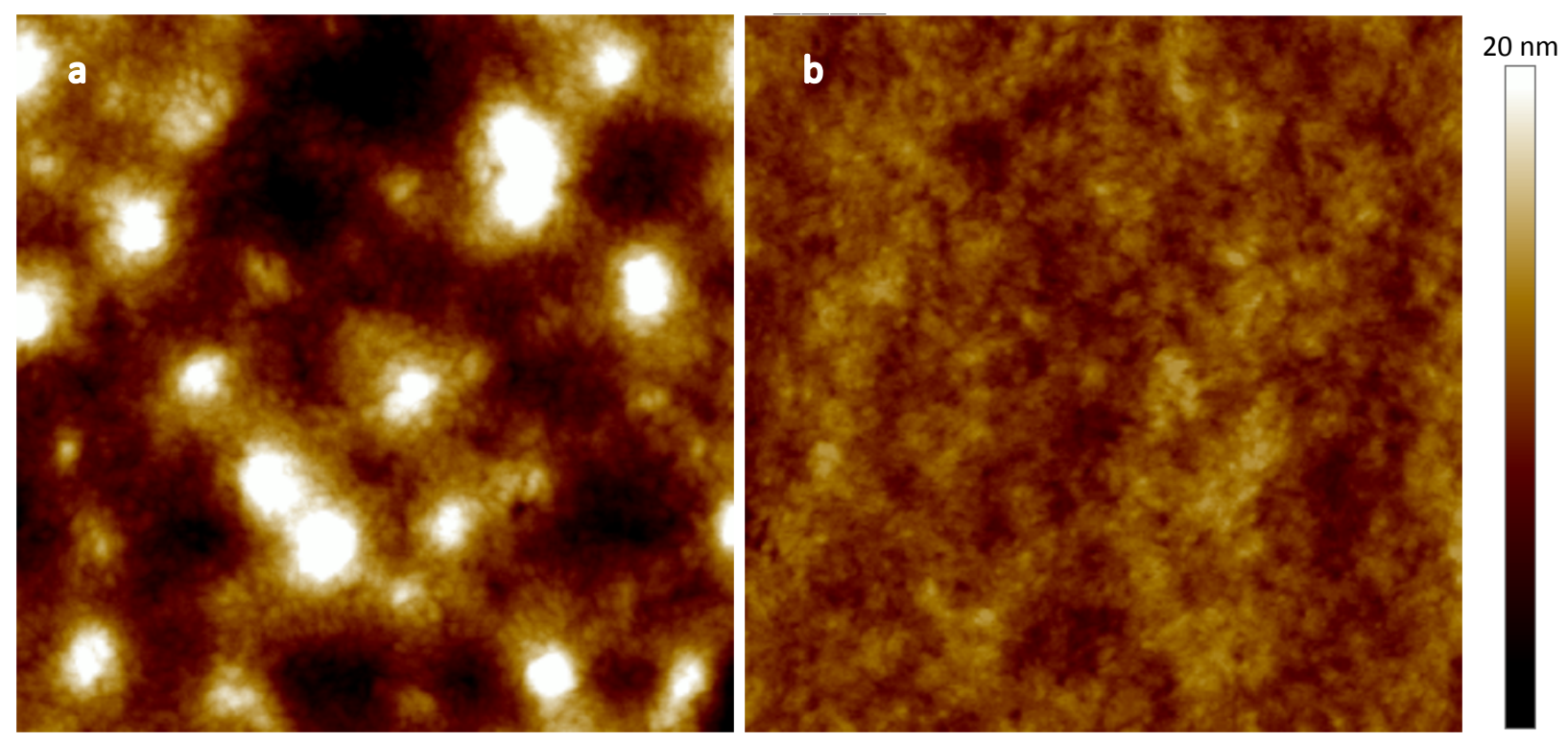

Fig. 5. AFM height images of P(T-DPP):PC ${ }_{71} \mathbf{B M}$ and $\mathbf{P ( T T - D P P ) : P C} \mathbf{7 1}_{11} \mathbf{B M}$ films. Polymer:PC ${ }_{71} \mathrm{BM}$ blend ratio is $1: 1.5$ with $2.5 \% \mathrm{v} / \mathrm{v}$ DIO. Image size: $2 \mu \mathrm{m} \times 2 \mu \mathrm{m}$. Height scale ranges from 0 to $20 \mathrm{~nm}$.

To further understand the intermolecular interactions in the polymers, GIWAXS experiments were performed on both pristine polymer and polymer:PCBM blend films to gain insight into the active layer nanostructures. As shown in Fig. 6, pristine films of both polymers showed reflection peaks at $\mathrm{Q}_{\mathrm{xy}}=\sim 0.29 \AA^{-1}$ along the in-plane (horizontal xy) directions (Fig. S6), corresponding to interchain d-spacings of $2.2 \mathrm{~nm}$. Another reflection peak at $\mathrm{Q}_{\mathrm{z}}=\sim 1.57 \AA^{-1}$ along the out-of-plane (vertical z) directions corresponds to $\pi$ - $\pi$ stacking distances of $4.0 \AA$. Since both polymers have their interchain lamellar stacking in the xy-directions and their $\pi-\pi$ stacking in z-directions, they are oriented face-on against the substrates, which is considered beneficial for an OPV device. Comparing P(T-DPP) to its corresponding non-alkylated version with $\pi-\pi$ stacking distance of $3.7 \AA$ and lamellar stacking distances of $1.74 \mathrm{~nm},{ }^{45}$ the polymer in this study with the additions of $n$-decyl side chains on the adjacent thiophene units experienced 

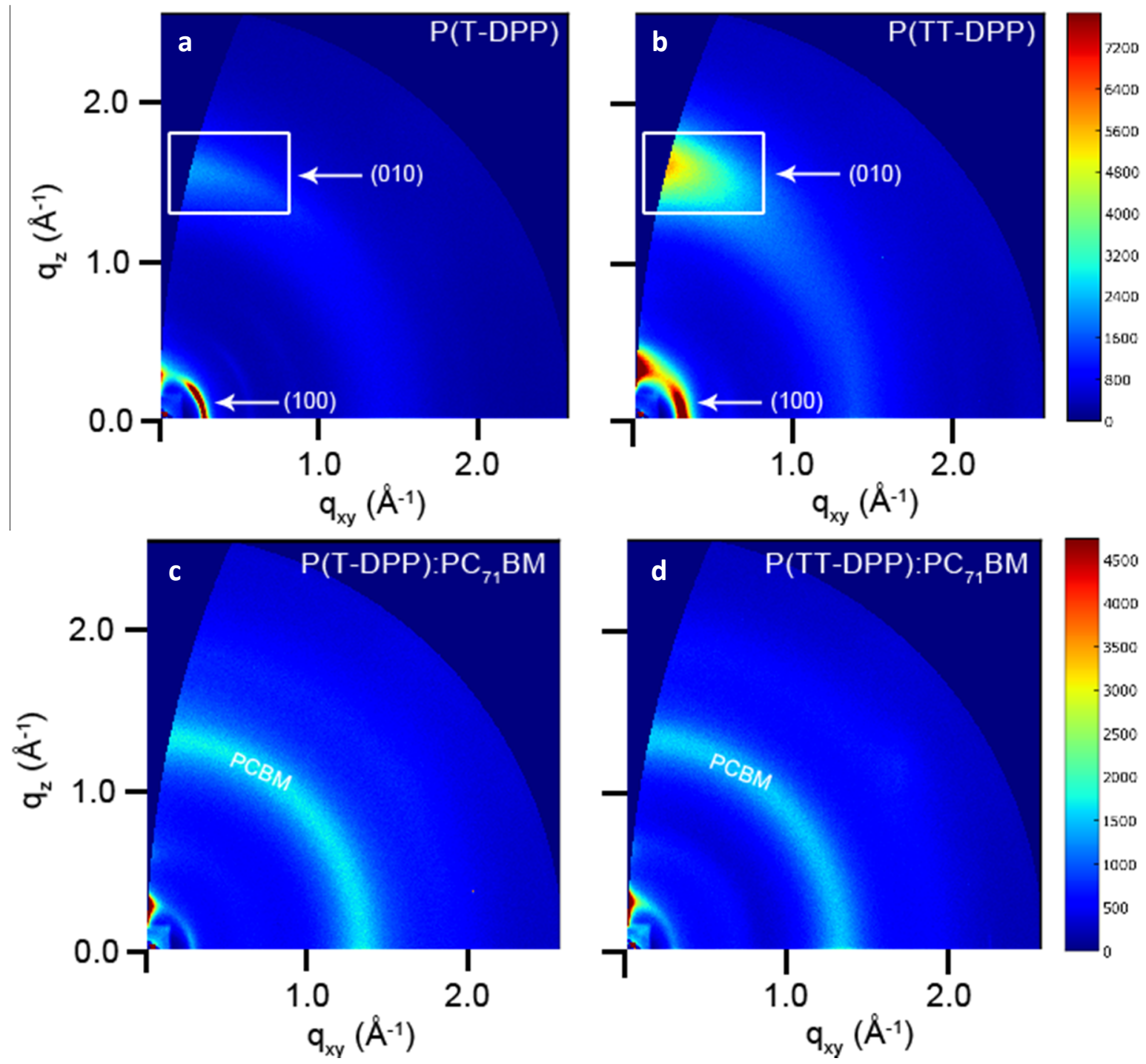

Fig. 6. Two-dimensional (2D) grazing incidence wide-angle X-ray scattering (GIWAXS) images of pristine (a) P(T-DPP), (b) P(TT-DPP), (c) P(T-DPP):PC ${ }_{71} \mathbf{B M}$, and (d) P(T-DPP):PC ${ }_{71} \mathbf{B M}$. Samples were spin-coated onto silicon substrates with the same condition as device fabrication. On the bottom are their respective images for 1:1.5 polymer:PC ${ }_{71} \mathrm{BM}$ blends with $2.5 \% \mathrm{v} / \mathrm{v}$ DIO.

increased intermolecular distances, leading to higher $\pi-\pi$ and lamellar stacking distances. As illustrated in Fig.1, the added side chains extend from the polymer backbones, increasing the intermolecular packing distances. In the polymer:PCBM blends, the diffractions from the $\pi-\pi$ 
stacking and interchain lamellar stacking disappear and are replaced by amorphous diffractions from the PCBM aggregates as seen in fig $6 \mathrm{c}$ and $\mathrm{d}$, indicating that the active layer blends are more disordered than the pristine polymers.

\section{CONCLUSIONS}

To investigate the effect of alkyl chains on DPP, we synthesized two polymers with $n$-decyl side chains attached to the two thiophene units directly adjacent to the DPP cores. Thiophene and thienothiophene were selected as the donor units for the polymers to ensure backbone planarity. Both polymers possessed low energy gaps extending into the infrared regions and high degrees of orders resulting from their planar structures. In thin-films, both polymers oriented face-on with respect to the substrates, which is considered advantageous for vertical charge transport in OPV devices. P(TT-DPP) showed a higher device performance as a result of the higher short circuit current density. This improved performance corresponded to higher charge transport and extraction efficiencies resulting from optimal domain sizes and a higher degree of interpenetrated networks of the donor and acceptor moieties within the active layer. The additional n-decyl side chains increase the intermolecular packing distances in both polymers and can be used strategically to control intermolecular stacking distances.

\section{Acknowledgment}

This work was supported by the Office of Naval Research (Grant award No. N00014-14-10173). We would like to thank The DOW Chemical Company for the gel permeation chromatography analyses. 


\section{References}

(1) Søndergaard, R. R.; Hösel, M.; Krebs, F. C. J. Polym. Sci., Part B Polym. Phys. 2013, 51, $16-34$.

(2) Amb, C. M.; Craig, M. R.; Koldemir, U.; Subbiah, J.; Choudhury, K. R.; Gevorgyan, S. A.; Jørgensen, M.; Krebs, F. C.; So, F.; Reynolds, J. R. ACS Appl. Mater. Interfaces 2012, $4(3), 1847-1853$.

(3) Nielsen, T. D.; Cruickshank, C.; Foged, S.; Thorsen, J.; Krebs, F. C. Sol. Energy Mater. Sol. Cells 2010, 94 (10), 1553-1571.

(4) Yu, G.; Gao, J.; Hummelen, J. C.; Wudl, F.; Heeger, A. J. Science (80-. ). 1995, 270, 1789-1791.

(5) Morin, P.-O.; Bura, T.; Leclerc, M. Mater. Horiz. 2015.

(6) Huo, L.; Hou, J.; Chen, H.-Y.; Zhang, S.; Jiang, Y.; Chen, T. L.; Yang, Y. Macromolecules 2009, 42, 6564-6571.

(7) Winder, C.; Sariciftci, N. S. J. Mater. Chem. 2004, 14, 1077-1086.

(8) Zhang, G.; Fu, Y.; Xie, Z.; Zhang, Q. Sol. Energ. Mat. Sol. Cells 2011, 95, 1168-1173.

(9) Dou, L.; Liu, Y.; Hong, Z.; Li, G.; Yang, Y. Chem. Rev. 2015, 115 (23), 12633-12665.

(10) Jung, J. W.; Jo, J. W.; Jung, E. H.; Jo, W. H. Org. Electron. 2016, 31, 149-170.

(11) Parnum, D. G.; Mehta, G.; Moore, G. G. I.; Siegal, F. P. Tetrahedron Lett. 1974, 29, 2549-2552.

(12) Iqbal, A.; Jost, M.; Kirchmayr, R.; Rochat, A. Bull. Soc. Chim. Belg. 1988, 97, 615-643.

(13) Grzybowski, M.; Gryko, D. T. Adv. Opt. Mater. 2015, 3, 280-320.

(14) Meager, I.; Ashraf, R. S.; Rossbauer, S.; Bronstein, H.; Donaghey, J. E.; Marshall, J.; Schroeder, B. C.; Heeney, M.; Anthopoulos, T. D.; McCulloch, I. Macromolecules 2013, 46, 5961-5967.

(15) Naik, M. a.; Patil, S. J. Polym. Sci. Part A Polym. Chem. 2013, 51 (20), 4241-4260.

(16) Choi, S.; Park, G. E.; Shin, J.; Um, H. A.; Cho, M. J.; Choi, D. H. Synth. Met. 2016, 212 , 167-173.

(17) Lee, G.-Y.; Han, A.-R.; Kim, T.; Lee, H. R.; Oh, J. H.; Park, T. ACS Appl. Mater. Interfaces 2016, 8, 12307-12315.

(18) Gevaerts, V. S.; Herzig, E. M.; Kirkus, M.; Hendriks, K. H.; Wienk, M. M.; Perlich, J.; Müller-Buschbaum, P.; Janssen, R. a J. Chem. Mater. 2014, 26, 916-926.

(19) Qu, S.; Tian, H. Chem. Commun. 2012, 48 (25), 3039.

(20) Li, Y. N.; Sonar, P.; Murphy, L.; Hong, W. Energy Environ. Sci. 2013, 6, 1684-1710.

(21) Li, W.; Hendriks, K. H.; Wienk, M. M.; Janssen, R. A. J. Acc. Chem. Res. 2016, 49, 7885 . 
(22) Choi, H.; Ko, S.; Kim, T.; Morin, P.; Walker, B.; Lee, B. H.; Leclerc, M.; Kim, J. Y.; Heeger, A. J. Adv. Mater. 2015, 27, 3318-3324.

(23) Liu, C.; Wang, K.; Gong, X.; Heeger, A. J. Chem. Soc. Rev. 2015, DOI: 10.1039/C5CS00650C.

(24) Liu, P.; Dong, S.; Liu, F.; Hu, X.; Liu, L.; Jin, Y.; Liu, S.; Gong, X.; Russell, T. P.; Huang, F.; Cao, Y. Adv. Funct. Mater. 2015, 25, 6458-6469.

(25) Duhheli, M.; Eteish, M. Z.; Hayoz, P.; Aebischer, O. F.; Turon, M. F.; Turbiez, M. G. R. Diketopyrrolopyrrole Polymers for Use in Organic Semiconductor Devices. EP2007/056102, 2009.

(26) Subramaniyan, S.; Xin, H.; Kim, F. S.; Jenekhe, S. A. Macromolecules 2011, 44, 62456248.

(27) Kim, K.-H.; Yu, H.; Kang, H.; Kang, D. J.; Cho, C.-H.; Cho, H.-H.; Oh, J. H.; Kim, B. J. J. Mater. Chem. 2013, 1, 14538-14547.

(28) Helgesen, M.; Carlé, J. E.; dos Reis Benatto, G. a.; Søndergaard, R. R.; Jørgensen, M.; Bundgaard, E.; Krebs, F. C. Adv. Energy Mater. 2015, 5, 1401996.

(29) Zalesskiy, S. S.; Ananikov, V. P. Organometallics 2012, 31, 2302-2309.

(30) Turbiez, M.; Leeuw, D. M. De; Janssen, A. J. J. Am. Chem. Soc. 2009, 131, 16616-16617.

(31) Zhang, L.; Tajima, K.; Hashimoto, K. Macromolecules 2011, 44, 4222-4229.

(32) Bijleveld, J. C.; Verstrijden, R. a. M.; Wienk, M. M.; Janssen, R. A. J. J. Mater. Chem. 2011, 21, 9224-9231.

(33) Zoombelt, A. P.; Mathijssen, S. G. J.; Turbiez, M. G. R.; Wienk, M. M.; Janssen, R. a. J. J. Mater. Chem. 2010, 20, 2240-2246.

(34) Kuwabara, J.; Nohara, Y.; Choi, S. J.; Fujinami, Y.; Lu, W.; Yoshimura, K.; Oguma, J.; Suenobu, K.; Kanbara, T. Polym. Chem. 2013, 4, 947.

(35) Holze, R. Organometallics 2014, 33, 5033-5042.

(36) Guo, X.; Zhou, N.; Lou, S. J.; Smith, J.; Tice, D. B.; Hennek, J. W.; Ortiz, R. P.; Navarrete, J. T. L.; Li, S.; Strzalka, J.; Chen, L. X.; Chang, R. P. H.; Facchetti, A.; Marks, T. J. Nat. Photonics 2013, 7, 825-833.

(37) Lee, J. K.; Ma, W. L.; Brabec, C. J.; Yuen, J.; Moon, J. S.; Kim, J. Y.; Lee, K.; Bazan, G. C.; Heeger, A. J. J. Am. Chem. Soc. 2008, 130 (11), 3619-3623.

(38) Love, J. A.; Collins, S. D.; Nagao, I.; Mukherjee, S.; Ade, H.; Bazan, G. C.; Nguyen, T.Q. Adv. Mater. 2014, 26, 7308-7316.

(39) Gupta, D.; Mukhopadhyay, S.; Narayan, K. S. Sol. Energy Mater. Sol. Cells 2010, 94 (8), 1309-1313.

(40) Tsang, S.-W.; Chen, S.; So, F. Adv. Mater. 2013, 25, 2434-2439.

(41) Qi, B.; Wang, J. J. Mater. Chem. 2012, 22, 24315-24325.

(42) Huang, D.; Li, Y.; Xu, Z.; Zhao, S.; Zhao, L.; Zhao, J. Phys. Chem. Chem. Phys. 2015, 17, 8053-8060.

(43) Li, Y.; Chen, Y.; Liu, X.; Wang, Z.; Yang, X.; Tu, Y.; Zhu, X. Macromolecules 2011, 44, 
6370-6381.

(44) Zhou, H.; Yang, L.; Xiao, S.; Liu, S.; You, W. Macromolecules 2010, 43 (2), 811-820.

(45) Homyak, P.; Liu, Y.; Liu, F.; Russel, T. P.; Coughlin, E. B. Macromolecules 2015, 48, 6978-6986. 